\title{
EFFECTS OF COUNSELLING TECHNIQUES IN REHABILITATING EMOTIONAL MALADJUSTMENT PROBLEM AMONG ADOLESCENTS
}

\author{
OLIHA, Mrs. J. A. \\ Department of Education Psychology and Curriculum Studies \\ Faculty of Education \\ University of Benin, Benin City \\ e-mail: $\underline{\text { mrsjosphineoliha@yahoo.co.uk }}$ \\ and \\ AUDU, Mrs. V. E. I. \\ Lecturer \\ Department of Education Psychology and Curriculum Studies \\ Faculty of Education \\ University of Benin, Benin City \\ e-mail: viviaudu@yahoo.com
}

\begin{abstract}
This study investigated the effectiveness of Rational Emotive therapy (RET) and Systematic Desensitization (SD) in promoting emotional adjustment among adolescents in Edo state. Quasi Experimental design was used for the study. A total number of eighty four (84) students were randomly selected for the study and three (3)Senior secondary schools were involved in Edo state. The instrument used for the study was Emotional Adjustment Inventory (EAI) based on anxiety, stress and depression. T-test statistics was used to analyze the data and to guide the study three hypotheses were formulated. The result showed a significant difference in the level of depression, stress and anxiety as compared to their counterpart not treated. Based on the findings recommendations were given.
\end{abstract}

Key words: Emotional adjustment, Adolescence, Depression, Stress, Anxiety, Counselling technique.

\section{Introduction}

Life is a journey that is full of varying experiences of course, not many youths regard all of these experiences as exciting. Some see most 
experiences of life as unfortunate. Experience means different things to people depending on their attitude and perspective. One major experience that stagnates people in life, which makes them feel depressed and conclude that nothing more can happen for them is emotional adjustment problem. Emotional adjustment problem is defined as a disorder or behavioural reaction to an identifiable stressful event or change in a person's life that is considered maladaptive to event or change. In psychology, the behaviour process by which humans maintain equilibrium among their various needs or between their needs and the obstacles of their environment. Where this adjustment fails, maladjustment occurs and severe adjustment crises lead to profound psychological disturbances in some people. A youth with emotional adjustment often experiences feelings of depression, stress, anxiety or combined depression and anxiety. As a result, that person may act out behaviourally against the rules and regulations of the school, family or society. In some youths, an emotional adjustment may manifest itself in such behaviours as skipping school, unexpected fighting, recklessness or criminal problems. Others however instead of acting out, may tend to withdraw socially and isolate themselves during their adjustment problems. Invariably, the effect of this situation is remarkably felt on the adolescent's academic achievement. Researchers have shown that students who are maladjusted do not perform well in examination. Constant poor grade is their lot and this resorts to depression (Osarenren, 1996). Depression, arising from academic aspect of the students' lives creates emotional adjustment problems. This in turn affects all the three learning stages of acquisition retention and recall. Since the affected students may possess feelings of unworthiness and self-reproach; and sees learning as punishment, in some cases the student becomes vulnerable to threat and frustration.

Adolescents experience both positive emotional states of happiness and peace, and the negative emotional states of anxiety, depression and stress. Adolescents must learn to react and deal with these emotional states in their daily living. How successful they meet these emotional demands is a measure of their capabilities to adjust. Again adolescence is a period marked by significant psychological transformation that occurs amid rapid pubertal growth including identity formation, individuation from parents and the establishment of intimate friendship. Tension is normative as the individual traverses these changes; however youths are out for adjustment difficulties if developmental change is accompanied by multiple spheres of the adolescent. The beginning of adolescence can mean facing up to some very adult psychological problems. One of these 
problems is depression, which is characterized by feelings of guilt, a loss of interest in activities, sleep problem and even suicidal thoughts.

Emotionally maladjusted adolescents are found almost in every classroom, home and even in the streets. The irony about the emotionally maladjusted youth is that the school curriculum does not make special or adequate provision for their training. The consequence is that the special attention which they need most is never given to them. Worse still, is the fact that they are labelled differently even by interest groups. At home, they are referred to as stubborn children. If they break the law, the Judge calls them delinquent. The social worker and counsellor see them as withdrawn and introverted, and the teacher labels them as rebellious (Adima, 1989). With these different labels they are treated differentially by various significant others depending on how they are perceived. Often times the teachers are confused on what to $d$ with such adolescents and other non-conforming teenagers. Thus, they are either neglected, or such misbehaviour on their part is promptly punished. From the psychological point of view, the use of punishment does not help to promote emotional adjustment among such teenagers (Adomeh, 1997).

The path of remediation when adolescents are faced with severe emotional adjustment problems is extensive. When the casual factor is a deep-seated psychological father appropriate counselling strategies must be used.

It is pertinent to note that at adolescence, youngsters start to organize and harmonize their emotional feelings. Their limited life experiences and dependence on significant others do not make it a smooth process for them. The result is that instead of becoming stable and emotionally well adjusted individuals. Many adolescents often display primitive instincts without control. Some adolescents struggle with their problems alone. There may be loneliness, daydreaming, alienation or withdrawal from friends, apathy, a forsaking of usual interests and activities, or perpetual inner turmoil that sometimes appears in the form of psychosomatic illness, anxiety, scholastic failure or more serious emotional and behavioural problems. Depression, anxiety and unexplainable changes in mood or behaviour tend to be common in adolescence, but these are not pathological unless they are prolonged and intense. More common are the adjustment reactions of adolescence. These come in response to stress and are characterized by irritability, persisting depression, brooding and temper outbursts (McCoy, 1982).

In an attempt to solve these emotional adjustment problems, some turn to drug use and alcohol use. These emotional adjustment problems 
are creating nightmares for parents, teachers and society since such youth sometimes turn to armed robbery, kidnapping as a way of life, this becoming a threat to law-abiding citizens. To help the youth overcome these emotional problem psychologists have in recent past risen to these challenges by developing theories to assist such emotionally maladjusted individuals in the society. Notable among these are Behaviour theory, Gestalt theory, Rational Emotive therapy and Transactional Analysis (Nwokwule, 1991). In this study, the researcher used two of these strategies they are; rational-emotive therapy and systematic desensitization.

\section{Statement of the Problem}

Adolescence is a time of frequent turmoil, frustration, insecurity and struggle with so many major conflicts, decisions and developmental tasks, the adolescent has to face his journey from puberty to adult in turbulent. Thus, the most difficult developmental period is probably adolescence. As a result, psychologists have described adolescence as a period of "storm and stress" a period of dramatic ups and downs through which every teenager must pass in order to develop into a mature adult.

Crisis develops from the onset of puberty manifesting in bodily changes and secretion of hormones and physical maturity when the cognitive maturity is still to come. The glandular changes bring about heightened emotionality. To psychologists, heightened emotionality extending over a period of time could be a danger.

Anxiety, depression, stress and even insecurity are emotional adjustment problems that affect the adolescents and the society. The emotionally maladjusted adolescent is an unhappy adolescent. And his problems certainly demand attention if for no other reason at least on humanitarian grounds. Since the dividing line between the emotionally maladjusted adolescent and juvenile delinquent adolescent could be a very tenuous one, the former may be considered as unidentified delinquent. The emotionally maladjusted adolescent is more or less a social evil since he is likely to carry his problems into adulthood. His emotional adjustment problems could affect school adjustment and school performance (Adomeh, 1993). In school examination is a necessary evil and it creates strain and stress in the mind of the students. A constant anxiety is produced by it students work under excessive strain and stress during examination. These can lead to anxiety, depression, unhappiness, insecurity and lack of self-confidence which can manifest in failure. Sometimes Education helps to split adolescents' world into three, namely the worlds of education, examination and work (Okoh, 1983). It takes 
counselling to bring to the knowledge of the adolescent that there is only one world-the world of life. The parents and the classroom teachers lack the essential tools for handling apparent and complete emotional adjustment problems which the adolescent may display in the home and school. It becomes therefore very necessary for the clinically minded counsellors to apply the robust scientifically tested technique to modify or even change emotionally maladaptive behaviour to socially accepted one. In pursuit of this aim the study seek to establish the efficacy of Rational Emotive therapy and Systematic Desensitization in rehabilitating emotional adjustment among adolescents.

\section{Research Hypotheses}

To guide the study three hypotheses were formulated

1. There is no significant difference between experimental depression students and those of the control group.

2. There is no significant difference between experimental anxiety students and those of the control group.

3. There is no significant difference between experimental stress students and those of the control group.

\section{Significance of the Study}

An experimental study of this nature would be significant for adolescents (with or without adjustment problems), their parents, classroom teachers, school counsellors and the society in general.

The finding of this study will be of immense benefits to educationists, administrators, curriculum planners and the government. Specifically, it will help them set out plans on how to modify the emotionally disturbed students and reintegrate them back to the school system.

\section{Method of Study}

The study is quasi - experimental pretest posttest control group research. The population comprised of all senior secondary school students in oredo local government area of Edo State. Eighty four (84) students were selected through simple systematic random sampling technique from three co - educational secondary schools in Oredo with twenty eight students from each school. The same method was used to select twenty eight senior students into each of the three groups after the pretest assessment. The sample size of this study therefore is 84 subjects. The instruments used for the study is emotional adjustment inventory in form 
of a 4 point Likert scale of a SA, A, D, SD adapted from Odebunmi (1991).Based on Psychological test scale for counselling and health management. Each of the scale consists of twenty items. The scales aim at surveying the respondents' level of anxiety, depression, and stress in order to understand his or her emotional adjustment patter in relations to these emotional indices. Rational emotive behaviour therapy and systematic desensitization was employed for the treatment intervention in each of the three schools. The participants were pretested two weeks before the experimental treatment was carried out and were all assigned to treatment group. The experimental participants were exposed to six treatment sessions spread over twelve weeks with an average of two (2) hours per session. The post treatment session was carried out two weeks after the last treatment session. The data was analyzed using the independent $\mathrm{t}$-test.

\section{Treatment}

\section{Rational Emotive Therapy}

Rational emotive behaviour therapy focuses on uncovering irrational beliefs which may lead to unhealthy negative emotions and replacing them with more productive rational alternatives REBT views human beings as responsibly hedonistic in the sense that they strive to remain alive and to achieve some degree of happiness. However, it also holds that humans are prone to adopting irrational beliefs and behaviour which stand in the way of their achieving their goal and purpose. Often these irrational attitudes or philosophies take the form of extreme or dogmatic 'must', 'should' or 'ought to'; they contrast with rational and flexible desires, wishes, preferences and wants. The presence of extreme philosophies can makes all the difference between healthy negative emotions (such as sadness or remorse or concern) and unhealthy negative emotions (such as depression or guilty or anxiety). This therapy aim at teaching subjects how to change their irrational thinking styles and give rational explanation to their behaviour problem.

\section{Systematic Desensitization}

Systematic Desensitization developed by Joseph Wolpe, is a behavioural therapy that is used in the treatment of phobias, it helps people to overcome fear and anxiety. Systematic Desensitization refers to a package of therapeutic procedures developed to treat problems in which maladaptive learned anxiety is central SD procedure involves the paring of muscle relaxation with imagined scenes of the situation generating anxiety in the client. The client first learns and practices an adaptive 
response that is incompatible with anxiety. Often this response is deep muscle relaxation. Second, the stimuli that make the client anxious are gradually exposed to successively more anxiety - evoking stimuli while performing the incompatible response. The client is thus desensitized to fear - evoking stimuli. Systematic Desensitization teaches participant how to eliminate a negative emotional state through training in muscle relaxation and anxiety hierarchy construction.

\section{Session one}

Topic: - Introduction and explanation of treatment programme

The participants were introduced to the facilitator and to one another as exclusive members of the group. The facilitator established rapport with the members of the group and solicited their co-operation on confidentiality of treatment materials and methods, punctuality, full participation all through the session and regular attendance. The participants and the facilitator agreed on time for therapy sessions. The treatment programmes were introduced to the group participants were encouraged to ask questions to clear any doubt.

\section{Sessions two and three}

Topic: - The Purpose of Counselling Therapy and its relevance in promoting students Emotional Adjustment Problem

The facilitator explained rational emotive behaviour therapy and Systematic Desensitization therapy basic assumptions about human nature. Their enumeration and discussion were to aid the subjects in understanding the theories during the sessions subjects were assigned home works which were discussed during subsequent sessions.

\section{Sessions four and five}

Topic: - Enumeration of Six RET Illogical Ideas and the Three Steps in the use of SD

The Facilitator enumerated the six illogical ideas of rational emotive therapy and led the participant in discussing the illogical idea that people perpetuate. He/she also explain the three steps involve in systematic Desensitization e.g. relaxation training, development of the anxiety hierarchy and systematic desensitization proper. At the end of the interaction all participants were asked to list illogical ideas which they intend to overcome their learnt and observed. 


\section{Sessions six and seven}

Topic: - Enumeration of Last Six RET Illogical Ideas and Muscle relaxation Training.

The facilitator brain storm the participant on previous treatment by asking them to list the six of the illogical ideas people perpetuate, lead them into discussing that last six illogical ideas e.g.

(a) You should have supernatural power of high degree of order before you feel comfortable.

(b) Your Self- worth depends on your performance and people's approval.

Teach them the A-B-C-D-E theory of Ellis where $\mathrm{A}=$ Activate events or experience $B=$ Belief system of individual (which is either rational or irrational) $\mathrm{C}=$ Consequence $\mathrm{D}=$ Disputable beliefs $\mathrm{E}=$ Effect of disputing irrational beliefs.

The facilitator also explains Deep Muscle relaxation. Deep Muscle relaxation is the most frequently used response to counter anxiety in Systematic Desensitization. Clients learn deep muscle relaxation by first tensing and then relaxing various muscle groups. The aim is to learn to discriminate between tension and relaxation, which helps the client achieve the later. This is to help participant reorganize their irrational and illogical thoughts and to counter their anxiety.

\section{Sessions eight to eleven}

Topic: - Internalizing logical and Rational Ideas and Constructing Anxiety Hierarchy.

Facilitator leads the subjects through both cognitive and emotive strategies as means of building a sound philosophy for living by internalizing rational and logical ideas. Tell them to name three cognitive and emotive strategies in RET. lead the subject to identify the anxiety eliciting stimuli then ranked them in the amount of anxiety they evoke, thereby forming an anxiety hierarchy. Provides examples of anxiety hierarchies lead them to pair the muscle relaxation with imagined scene of the situation generation anxiety in the client.

\section{Session twelve}

Topic: - Administration of Emotional Adjustment Inventory to Obtain Post - test Scores.

The emotional adjustment inventory was administered to the students to obtain the post - test scores. The inventories were collected after the 
students filled them. The facilitator expressed gratitude to the members of the group for their co -operation.

\section{The Control Group}

No treatment was applied to this group since it served as control to the experimental group; however time was spent with the group discussing issues on daily health care.

\section{Results}

The results are presented in Tables 1-3. The interpretation of each result follows the tables.

\section{Hypothesis I}

There is no significant difference between experimental depression students and those of the control group.

Table 1: t-test post-test depression mean scores based on the treatment technique and control group.

\begin{tabular}{|l|c|c|c|c|c|c|}
\hline \multicolumn{1}{|c|}{$\begin{array}{c}\text { Treatment } \\
\text { Group }\end{array}$} & N & Mean & SD & df & T & P \\
\hline RET - depression & 28 & 46.5 & 6.87 & 54 & & \\
Pre - 21.42 & sig \\
Post - depression & 28 & 33.85 & 3.04 & 54 & & \\
\hline SD & & & & & & \\
Pre - depression & 28 & 46.29 & 5.01 & 54 & 22.55 & sig \\
Post - depression & 28 & 32.76 & 5.16 & 54 & & \\
\hline Control & & & & & & \\
Pre- Test & 28 & 44.32 & 6.48 & 54 & 0.79 & \\
Post - Test & 28 & 44.35 & 5.64 & 54 & & \\
\hline
\end{tabular}

From the above table the following results were obtained.

1. Subjects treated with RET programme when compared with those in the control group at post-treatment it evidenced a significantly lower level of depression.

2. Subjects treated with the SD programme when compared with those in the control group at post-treatment also evidenced a significantly lower level of depression.

3. A comparison of the pre-treatment and post-treatment depression scores of students in the control group shows that there was no 
significant improvement. From the above analysis, there was a significant difference between the treated and non-treated. It was concluded that the administered treatments were efficacious in reducing depression among students.

\section{Hypothesis II}

There is no significant difference between experimental anxiety students and those in the control group.

Table 2: $\mathrm{t}$ - test, post - test anxiety mean scores based on the treatment technique control group

\begin{tabular}{|c|c|c|c|c|c|c|}
\hline $\begin{array}{l}\text { Treatment } \\
\text { group }\end{array}$ & $\mathbf{N}$ & Mean & S.D & df & $\mathbf{t}$ & P value \\
\hline RET & & & & & \multirow{3}{*}{24.3} & \multirow[b]{3}{*}{ Sig } \\
\hline Pre- Anxiety & 28 & 50.04 & 4.44 & 54 & & \\
\hline Post- Anxiety & 28 & 37.89 & 2.59 & 54 & & \\
\hline S.D & & & & & \multirow{3}{*}{22.55} & \multirow{3}{*}{ Sig } \\
\hline Pre- Anxiety & 28 & 50.11 & 4.21 & 54 & & \\
\hline Post- Anxiety & 28 & 37.62 & 3.07 & 54 & & \\
\hline Control & & & & & \multirow{3}{*}{0.12} & \\
\hline Pre- Anxiety & 28 & 48.86 & 5.19 & 54 & & \\
\hline Post- Anxiety & 28 & 48.54 & 3.65 & 54 & & \\
\hline
\end{tabular}

From the above table, the following results were obtained.

1. Students treated with RET programme had a lower level of anxiety compared with the control group student at post-test.

2. Students treated with SD programme also had a lower level of anxiety when compared with the control group students after treatment.

3. A comparison of the pre-treatment and post-treatment anxiety scores of students in the control group shows no significant improvement.

From the above analysis it shows that there is a significant difference in the anxiety level of students treated. It therefore means that RET and SD are effective in reducing anxiety level among students.

\section{Hypothesis III}

There is no significant difference between the experimental stress students and those if the control group. 
Table III: $\mathrm{t}$-test comparison of post-test stress means based on treatment

\begin{tabular}{|l|c|c|c|c|c|c|}
\hline \multicolumn{1}{|c|}{$\begin{array}{c}\text { Treatment } \\
\text { group }\end{array}$} & N & Mean & S.D & Df & t & P value \\
\hline RET & 28 & 44.18 & 4.42 & 54 & & \\
Pre & 28 & 34.36 & 4.31 & 54 & 17.54 & Sig \\
Post & 28 & 43.39 & 4.03 & 54 & & \\
\hline S.D & 28 & 34.35 & 4.61 & 54 & 17.42 & Sig \\
Pre & & & & & & \\
Post & 28 & 45.46 & 5.07 & 54 & 0.79 & \\
\hline Control & 28 & 44.72 & 6.12 & 54 & & \\
Pre & Post & & & &
\end{tabular}

The following result in table three showed that students treated with RET had a significant difference in level of stress compared with the control group because the calculated $t$ of 17.54 was far higher than the critical $t$ of 2.00 likewise those treated with SD. The result stated that the calculated $t$ is 17.42 while the table value $t$ is 2.00 at $p$ value of 0.05 .

The control group had no difference because the calculated $t$ of 0.79 was far lower than the table value $t$ of 2.00 .

\section{Discussion of Results}

Information from the three tables has revealed that Rational Emotive therapy (RET) and Systematic Desensitization (SD) led to the significant effect in the promotion of emotional adjustment among students. The finding of this study appears to be in harmony with the results of earlier studies on efficacy of counselling in treating clients with emotional problems (Ivery, 1962 and Lazarus, 1961). The results also agree with that of Adomeh (1997). In his report, he stated that the efficacy of counselling in fostering emotional adjustment among treated subjects is one of the basic reasons why the use of psychological tests is popular in counselling. He supports Nwabuolu and Odebunmi's position that less severe anxiety, depression and stress could be modified through psychotherapy. This finding attests to that of Palmer (1992) that the application of RET's paradigm and relaxation techniques to stressful situations proved effective in stress management strategies. The result of this study does not only show the effectiveness of RET and SD in the reduction of anxiety, depression and stress among students of the 
experimental groups, it also corroborates previous research findings (Cooke, 1968; Goldfried \& Trier, 1974).

In conclusion, students could be assisted to improve on their adjustment problem through the use of psychological strategies and the use of Rational Emotive therapy, Systematic desensitization is effective in rehabilitating adolescents with emotional adjustment problems.

\section{Recommendations}

Based on the findings of this study, it is recommended that

1. Rational Emotive therapy and systematic desensitization techniques should be adopted as an effective strategy for promoting emotionally maladjusted students.

2. Every school should be provided with school counsellors to help stop crude and ineffective way of handing emotionally maladjusted adolescent which even worsen their situation.

3. Another way of preventing the development of emotional adjustment problems in schools is the formation of group meeting where the students can interact in semi-controlled ways in order to improve their lifestyles.

\section{References}

Adima, E. E; (1989). Special Education. Ibadan: NPS Educational Publisher Ltd.

Adomeh, C. O; (1997). Differential effectiveness of Two counselling methods of fostering Emotional Adjustment among Adolescents unpublished PhD Thesis www.scribd.com/fostering .

Goldfried, M. R \& Trier, M. M; (1974). Reduction of Test Anxiety Through Cognitive Restructuring. Journal of Consulting and Clinical Psychology 48. 32-39.

Ivery, A. E; (1962). The Academic Performance of Students Counselled at a university counselling services. Journal of Consult Psychology 19.

Lazarus, A. A; (1961). Group Therapy of Public Disorders by Systematic Desensitization. Journal of Abnormal and Social Psychology 63. 504-510.

Looke, J. W; (1968). Adolescent fears Adolescence 2, (8) 459-468.

McCoy, K; (1982). Coping with Teenage Depression: A parent's guide (New York New American Library).

Nwokwule, I. N. S; (1991). The Nature and types of counselling Approaches An Invited paper presented at the seminar/workshop for counsellors/career teachers in post primary institutions in Edo state held at Idia College Benin city on $20^{\text {th }}$ of July. 
Okoh, S. E; (1983). Value in Counselling. In A. Uba (Ed.) Introduction to Counselling Ile-Ife. University of Ife Press.

Osarenren, N; (1999). Relationship between maladjustment problems and Academic Achievement among Urban and rural Adolescent. The Counsellor 17(1)

Palmer, S; (1992). Stress Management: A Course Reader. London The BPCC Wheatons Ltd. 